\title{
The multistage structural development of the Upper Weichselian Jasmund Glacitectonic Complex (Rügen, NE Germany)
}

\author{
Anna Gehrmann \\ Institute for Geography and Geology, University of Greifswald, Friedrich-Ludwig-Jahn-Str. 17a, 17487 Greifswald, Germany
}

Correspondence: Anna Gehrmann (anna.gehrmann@uni-greifswald.de)

Relevant dates: $\quad$ Received: 9 March 2020 - Revised: 13 May 2020 - Accepted: 19 May 2020 Published: 11 June 2020

How to cite: Gehrmann, A.: The multistage structural development of the Upper Weichselian Jasmund Glacitectonic Complex (Rügen, NE Germany), E\&G Quaternary Sci. J., 69, 59-60, https://doi.org/10.5194/egqsj-69-59-2020, 2020.

Supervisor: Martin Meschede (University of Greifswald) Co-Supervisors: Stig A. Schack Pedersen (Geological Survey of Denmark and Greenland), Chris Harding (Iowa State University)

Dissertation online: https://nbn-resolving.org/urn:nbn:de: gbv:9-opus-24751

Glacitectonic deformation in the late Weichselian caused the tectonic framework of large-scale folds and displaced thrust sheets of Maastrichtian (Upper Cretaceous) chalk and Pleistocene glacial deposits in the southwestern Baltic Sea area.

A wide spectrum of methods has been compiled to unravel the structural evolution of the Jasmund Glacitectonic Complex (JGC). The analyses of digital elevation models (DEMs) suggest a division into two structural sub-complexes - a northern part with composite ridges striking NW-SE and a southern part with SW-NE-trending ridges. Geological cross sections from the eastern coast (southern sub-complex) were constructed and restored using the software Move $\mathrm{e}^{\mathrm{TM}}$ and the complementary module 2D Kinematic Modelling ${ }^{\mathrm{TM}}$.

The final geometric model of the southern sub-complex shows a small-scale fold-and-thrust belt (Fig. 1a). It includes three different orders of architectural surfaces (Pedersen, 2014): erosional surfaces and the decollement (first order), thrust faults (second order), and beds outlining hanging-wall anticlines as well as footwall synclines (third order). Thrust faults of the southern structural sub-complex are mainly inclined towards the south, which indicates a local glacier push from the S-SE (Fig. 1a).

The glacitectonic structures have a surface expression in the form of subparallel ridges and elongated valleys in between. Geomorphological mapping and detailed landform analyses together with the structural investigations provide an insight into the chronology of sub-complex formation. The northern part of the JGC is suggested to have been formed first by an ice push from the NE, followed by the slightly younger formation of the southern sub-complex (Fig. 1b, c). Partly truncated northerly ridges and their superimposition by the southern sub-complex indicate this chronology. Crenulated ridges and anomalies in the structural configuration of the easternmost part of Jasmund suggest a third glacier push from E-ENE (Fig. 1d).

Although there is a high number of scientific publications on the glacitectonic evolution of Jasmund, these presented models often lack a consistent theory for the development integrating all parts of the $100 \mathrm{~km}^{2}$ large complex. Therefore, the combination of all results leads to a more self-consistent genetic model for the entire JGC.

Data availability. The data are publicly available via the thesis (dissertation online) and references therein. 


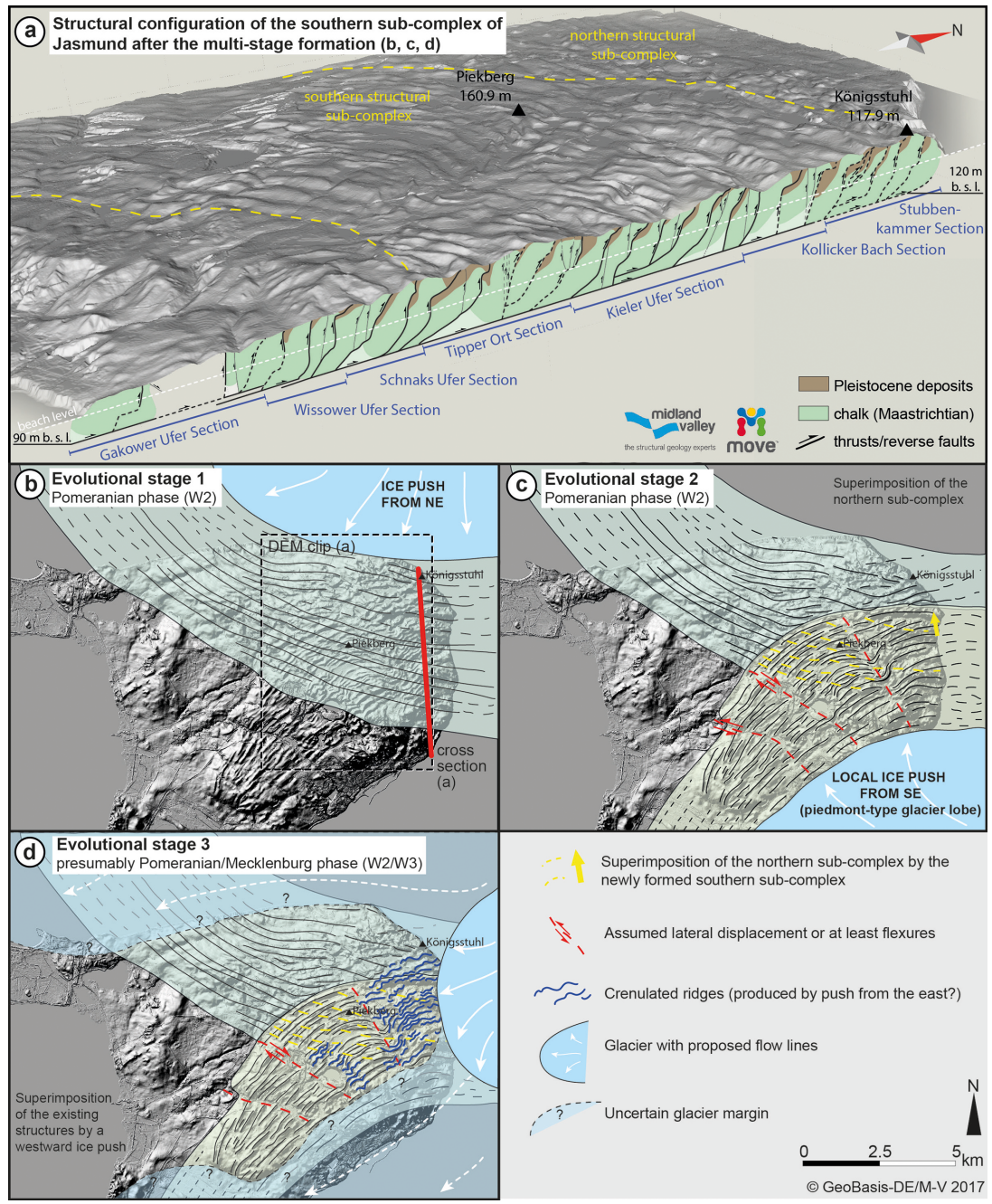

Figure 1. (a) Interpreted cross section of the southern structural sub-complex below the DEM of the JGC, which shows the main parts of the northern and southern ridge domain. The model is 2 times exaggerated. (b) First step of the multistage evolution of the JGC - formation of the northern sub-complex by a local ice push from NE. (c) Development of the southern sub-complex by a local ice push from SE leading to a partial truncation and superimposition of the northern ridge domain. (d) Minimum reconstruction of the ice front only touching the easternmost part of the JGC (light blue) and assumed wider glacier extent, which kind of envelops the complex (transparent light blue). The local ice push from E-ENE reshapes the quasi-straight ridges to wavy forms (DEM data provided by the LAiV M-V, modified after Gehrmann, 2018; Gehrmann and Harding, 2018).

Financial support. The article processing charge was funded by the Quaternary scientific community, as represented by the host institution of EGQSJ, the German Quaternary Association (DEUQUA).

Review statement. This paper was edited by Christopher Lüthgens and reviewed by one anonymous referee.

\section{References}

Gehrmann, A.: The multi-stage structural development of the Upper Weichselian Jasmund Glacitectonic Complex Rügen, NE Ger- many), Dissertation, Faculty of Mathematics and Natural Sciences, University of Greifswald, Germany, 2018.

Gehrmann, A. and Harding, C.: Geomorphological Mapping and Spatial Analyses of an Upper Weichselian Glacitectonic Complex based on LiDAR Data, Jasmund Peninsula (NE Rügen), Germany, Geosciences, 8, 208, https://doi.org/10.3390/geosciences8060208, 2018.

Pedersen, S. A. S.: Architecture of Glaciotectonic Complexes, Geosciences, 4, 269-296, https://doi.org/10.3390/geosciences4040269, 2014. 